\title{
ЭВОЛЮЦИЯ ПОЛОЖЕНИЯ ОФШОРНЫХ ЮРИСДИКЦИЙ В ГЛОБАЛЬНОЙ ЭКОНОМИКЕ
}

\section{DEVELOPMENT OF THE POSITION OF OFFSHORE JURISDICTIONS IN THE GLOBAL ECONOMY}

E. Trigub

Summary. Offshore jurisdictions are an integral part of the global economy in today's conditions. They have been functioning for several decades, and the attitude of stakeholders towards them has changed over the years. This is confirmed by the activation of the anti-offshore policy caused by the global economic crisis of 2008-2009. In this regard, the article analyzes the main changes in the policy of the worldwide community and individual countries in relation to offshores, as well as in the policy of low-tax jurisdictions.

Keywords: offshore jurisdictions, anti-offshore policy, automatic information exchange, preferential taxation, tax avoidance.

\section{Введение}

$\mathbf{0}$ фшорные юрисдикции стали неотъемлемой частью современных международных экономических отношений. Популярность офшоров не случайна и обусловлена тем, что их функционирование и развитие напрямую связаны с развитием глобализационных процессов. Их деятельность стимулирует либерализацию мировой экономики, которая, в свою очередь, является фактором воздействия на финансовую глобализацию [1, с. 35].

Значительным толчком для распространения офшоров в глобальном масштабе стало развитие информационных технологий в 1980-х гг., которые способствовали ускорению обращения капитала, а также активизации различных трансграничных финансовых потоков [2, с. 8].

Развитие международного бизнеса с использованием офшоров отличается своей стремительностью, которая подтверждается статистикой. Например, многонациональные компании (МНК), являющиеся ведущим институтом мировой экономики, только за период с 2015 г. по 2018 г. увеличили объемы прибыли, которые были переведены в офшорные юрисдикции, с 616 млрд. долл. до 946 млрд. долл. Данное значение, безусловно, значительное, поскольку оно составляет $36 \%$ от общей

\author{
Тригуб Екатерина Юрьевна \\ Аспирант, Финансовый университет при \\ Правительстве Российской Федерачии (Россия, \\ 2. Москва) \\ ekatrigub@mail.ru
}

Аннотация. Офшорные юрисдикции являются неотъемлемым элементом функционирования мировой экономики в современных условиях. Они реализуют свою деятельность уже несколько десятилетий, и за эти годы отношение заинтересованных сторон к офшорным юрисдикциям изменилось. Это подтверждается активизацией антиофшорной политики, вызванной мировым экономическим кризисом 2008-2009 гг. В связи С этим, в статье осуществляется анализ основных изменений в политике мирового сообщества и отдельных стран по отношению к офшорам, а также в политике самих низконалоговых юрисдикций.

Ключевые слова: офшорные юрисдикции, антиофшорная политика, автоматический обмен информацией, льготное налогообложение, уклонение от уплаты налогов.

прибыли МНК [3, с. 1]. Такая динамика увеличения объемов вывода прибыли, а также желание МНК вести бизнес в рамках офшорных юрисдикций вызвано получением целого ряда преимуществ, свойственных офшорам.

Несмотря на то, что единой дефиниции термина «офшор» не существует, и каждый автор в рамках своего исследования подразумевает под этим термином различные понятия, все же можно привести наиболее универсальное определение термина. Офшор - это государство (или его часть), для нерезидентов которого характерно предоставление:

- возможности по уменьшению налоговых и других платежей;

- анонимного осуществления финансовых операций и сокрытия реальных бенефициаров компаний;

- оптимальной правовой среды для ведения бизнеса, в том числе упрощенных условий административного и финансового контроля [4, с. 6].

Важно отметить, что с течением времени отношение к офшорным юрисдикциям у мирового сообщества и отдельных стран существенно изменилось. В связи с этим рассмотрим, как изменились политика заинтересованных сторон и подходы к оценке преимуществ офшоров, которые характерны для них при использовании физическими и юридическими лицами. 


\section{Анализ изменений коншепчий офшорных юрисАикций}

Для представителей бизнеса выгодно вести предпринимательскую деятельность в рамках офшорных юрисдикций в силу ряда вышеупомянутых преимуществ, однако далеко не для всех стран такие условия реализации бизнеса благоприятны. В целом, если некоторое время назад к преимуществам офшоров и мировое сообщество, и отдельно взятые оншорные государства относились более снисходительно, то сегодня осознание негативных черт офшорных юрисдикций и, исходящая из них, необходимость активизации антиофшорной политики как на национальном, так и особенно на международном уровне, позволяют сделать вывод о негативном отношении к офшорам.

Толчком к развитию деофшоризации ускоренными темпами послужил мировой экономический кризис 2008-2009 гг., ведь именно в этот период остро возросла потребность в новых источниках бюджетных доходов, в связи, с чем актуальным стало решение проблем с упускаемыми в силу офшорного функционирования статьями доходов и налоговой справедливостью.

Согласно докладу, опубликованному Tax Justice Network в ноябре 2020 г., МНК ежегодно переводят прибыль в размере 1,38 трлн. долл. в офшорные юрисдикции, в результате чего фискальные органы в мире теряют 245 млрд. долл. в виде прямых налоговых поступлений. Более того, их налоговые потери составляют еще 182 млрд. долл. в год в связи с уклонением физических лиц от уплаты налогов [5, с. 14].

В данном докладе также указано, что страны с более высокими доходами теряют больше прямых налоговых поступлений из-за злоупотреблений, связанных с уклонением от уплаты подоходных налогов корпораций, чем страны с более низким уровнем дохода. Потери первых составляют 202 млрд. долл. ежегодно, а вторых - 43 млрд. долл. Классификация стран по уровню доходов осуществляется Всемирным банком исходя из валового национального дохода на душу населения. При этом страны с более низким уровнем доходов в пропорциональном выражении, то есть в сравнении со всеми налоговыми убытками и поступлениями, лишаются большего объема налогов. Из-за уклонения от уплаты корпоративных налогов такие государства теряют 5,5\% в общем эквиваленте от собранных налогов, а страны с более высоким уровнем доходов - 1,3\%. Отсюда, злоупотребления, связанные с корпоративным налогом, наносят больший урон странам с низкими доходами, а значит в большей степени они заинтересованы в реформировании глобальной налоговой системы, целью которой является ликвидация налоговых уклонений, нежели государства с высоким уровнем доходов. Важно отметить, что на долю стран с высокими доходами приходится 98\% налогов корпораций, поступающих в офшорные юрисдикции, а на долю государств с низкими доходами - оставшиеся $2 \%$ [5, с. 15].

Вполне закономерно, что отношение разных заинтересованных сторон к офшорам и их преимуществам отличается в зависимости от стейкхолдера. Так, МНК получают выгоду от уменьшения налоговых и иных платежей, офшорные юрисдикции также остаются в выигрыше.

В свою очередь, размывание налогооблагаемой базы и вывод доходов из-под налогообложения негативно сказывается на государственных бюджетах оншорных юрисдикций в силу недополучения налоговых отчислений, при этом максимальное отрицательное влияние оказывается на развивающиеся страны, у которых в структуре бюджетных доходов превалирующую роль играют поступления от подоходных корпоративных налогов [6, с. 37].

На международном уровне с целью борьбы с этой проблемой в 2013 г. на саммите в Санкт-Петербурге «Большая двадцатка» поддержала инициативу Организации экономического сотрудничества и развития (ОЭСР) - План BEPS (Action Plan on Base Erosion and Profit Shifting). Работа по реализации Плана BEPS ведется на основании 15 ключевых направлений, осуществление которых позволит реализовать реформу международной налоговой системы. План BEPS подразумевает принятие мер в рамках разработки унифицированных стандартов налоговой отчетности для стран, избежания двойного налогообложения, ликвидации уклонения от уплаты налогов цифровыми компаниями, ужесточения трансфертного ценообразования и т.д.

Одной из целей Плана BEPS является модернизация существующей системы международных соглашений об избежании двойного налогообложения (СИДН), в связи с этим в июне 2017 г. 68 стран подписали Многостороннее Соглашение (Multilateral Instrument - MLI). Пункты Многостороннего соглашения включают требования по исключению предоставления налоговых льгот в случаях, когда это условие является одной из ключевых целей сделки, или, если в капитале компании свыше 50\% принадлежит резидентам другой юрисдикции. В этом соглашении содержатся также положения по поводу недвижимости, дивидендов и иных типов доходов. Отсюда, многостороннее соглашение позволяет государствам, в которых находится недвижимость облагать налогом прирост стоимости акций иностранных компаний, владеющих этой недвижимостью [7, с. 231]. 
Таблица 1. Ставки корпоративного подоходного налога в 2013 и 2020 гг.,\%

\begin{tabular}{|l|l|l|}
\hline Страна & $\mathbf{2 0 1 3}$ г. & $\mathbf{2 0 2 0}$ г. \\
\hline Соединенные Штаты Америки & 39,0 & 25,8 \\
\hline Франция & 38,0 & 32,0 \\
\hline Бельгия & 34,0 & 25,0 \\
\hline Норвегия & 28,0 & 22,0 \\
\hline Тунис & 30,0 & 25,0 \\
\hline Пакистан & 33,0 & 29,0 \\
\hline
\end{tabular}

Источник: составлено автором на основании [10].

Несмотря на то, что ужесточение мер по деофшоризации на международном уровне призвано решить ряд проблем, в том числе и проблему уклонения от уплаты налогов, к сожалению, активная политика в данном направлении несет за собой негативные последствия для оншорных государств. Например, антиофшорная политика стимулировала уменьшение разрыва значений ставок подоходных налогов офшорных и оншорных юрисдикций. Если раньше разница в ставках налога на прибыль корпораций между офшорными и оншорными юрисдикциями была слишком ощутимой, то на сегодняшний день она не столь велика.

В процессе борьбы с недобросовестной налоговой конкуренцией и «гонки на дно», когда государства, пытаясь конкурировать с низкими ставками налогов на прибыль офшорных юрисдикции, регулярно снижали значения своих ставок, корпоративные подоходные ставки налогов снижались. Безусловно, снижение ставок негативно сказывается на пополнении бюджетов оншорных государств, так как соответствующим образом уменьшаются объемы их налоговых поступлений. Отсюда, с 1985 г. по 2019 г. средняя мировая ставка корпоративного налога существенно уменьшилась с $49 \%$ до $23 \%$ [8, с. 1$]$.

Более того, в настоящее время согласно отчету Международного валютного фонда, опубликованному в феврале 2021 г., установленные законом ставки корпоративного подоходного налога в развитых и развивающихся странах составляют в среднем 22,3\% и 24\% соответственно, однако разброс значений этих ставок между разными странами все равно сохраняется большим $[9$, с. 34].

Примерами стран, которые за последние несколько лет снизили ставки корпоративного подоходного налога, являются: государства-члены «Большой семерки», такие как США и Франция; развитые страны в лице Бельгии и Норвегии; развивающиеся страны, к которым относятся Тунис и Пакистан. С 2013 по 2020 г. значения ставок корпоративного подоходного налога уменьши- лись в США с 39\% до 25,8\% и во Франции с 38\% до 32\%, а также в Бельгии с $34 \%$ до 25\% и Норвегии с $28 \%$ до $22 \%$ (Табл. 1). За аналогичный временной период снижение ставок подоходного налога наблюдалось в Тунисе (с $30 \%$ до 25\%) и Пакистане (с 33\% до 29\%).

Немаловажную роль в снижении разрыва между значениями ставок офшорных и оншорных юрисдикций играют и иные современные антиофшорные меры. Лидеры стран «Большой двадцатки» в конце октября 2021 г. на саммите в Риме приняли декларацию, согласно которой в 2023 г. вступит в силу реформа, касающаяся введения глобальной минимальной налоговой ставки на прибыль крупных МНК в размере 15\%. Ранее, в июне 2021 г. эту меру одобрили страны «Большой семерки», а в октябре инициативу поддержали 136 стран, на долю которых приходится более 90\% мирового ВВП [11].

В июне 2021 г. Налоговая обсерватория ЕС опубликовала на своем сайте доклад, в котором был осуществлен расчет величины дополнительных налоговых поступлений от корпоративных налогов в ЕС в случае введения ставки в 15\%. Согласно оценкам, применение налоговой ставки в 15\% к прибыли европейских МНК позволит фискальным органам ЕС получить 50 млрд. евро вдобавок к 340 млрд. евро, которые планируется собрать, исходя из действующего законодательства, в 2021 г. [12, с. 24-28].

\section{Гарантия конфиАеншиальности осушествляемых операций и реальных бенефициаров}

Если рассматривать такое преимущество офшорных юрисдикций, как сохранение конфиденциальности учредителей, бенефициаров и владельцев счетов, то с принятием Плана BEPS и других антиофшорных мер гарантия исполнения данного условия достаточно условна. И оншорные государства, и мировое сообщество в целом являются сторонниками искоренения анонимности реализуемых финансовых операций. 
Таблица 2. Сведения по поводу автоматического обмена финансовой и налоговой информацией за 2017-2019 гг.

\begin{tabular}{|l|l|l|l|}
\hline Год & $\begin{array}{l}\text { Юрисдикции, осуществляющие автоматический } \\
\text { обмен информацией }\end{array}$ & Финансовые счета, млн. & Двухсторонние отношения \\
\hline 2017 & 48 & 11 & 2600 \\
\hline 2018 & 96 & 47 & 4500 \\
\hline 2019 & 97 & 84 & 6100 \\
\hline
\end{tabular}

Источник: $[15$, с. 13].

Еще в 2009 г. с целью противодействия уклонения от уплаты налогов за счет офшоров «Большая двадцатка» объявила о прекращении существования банковской тайны, что дало возможность налоговым органам стран получать информацию об операциях, счетах и вкладах клиентов банков, являющихся нерезидентами этих денежно-кредитных институтов [13, с. 2]. До этого момента данная информация была конфиденциальной.

Кроме того, в 2014 г. ОЭСР утвердила инициативу в отношении осуществления автоматического обмена финансовой и налоговой информацией государствами на основании Единого стандарта отчетности (Common Reporting Standard - CRS). В рамках этой инициативы подразумевается получение фискальными органами сведений об активах и счетах физических и юридических лиц от других юрисдикций в автоматическом режиме [14, с. 42-43]. Налоговая прозрачность достигается странами за счет установления личности своих налоговых резидентов, имеющих счета за рубежом, и получения информации по поводу счетов и различных категорий их доходов, а именно дивидендов, процентов, роялти и др. Автоматический обмен информацией реализуется исходя из заключенных странами многосторонних и двухсторонних соглашений. Сведения, которые отправляются фискальным органам, формируются иностранными финансовыми институтами: банками, инвестиционными фондами, брокерами, страховыми компаниями и т.д.

Автоматический обмен финансовой и налоговой информацией юрисдикциями стал впервые осуществляться в 2017 г. Примечательно, что с течением времени количество юрисдикций, двусторонних соглашений и финансовых счетов неизменно увеличивалось. Если в 2017 г. всего 48 юрисдикций обменивались информацией, то в 2018 г. их стало уже 96, а в 2019 г.- 97 (Табл. 2). При этом обмен информацией реализовывался в 2017 г. в рамках 2600 двусторонних отношений по всему миру, а в 2019 г. уже за счет более чем 6000 двусторонних соглашений. За период 2017-2019 гг. фискальным органам удалось значительно увеличить объем получаемых сведений, так как в 2017 г. они полу- чили информацию всего о 11 млн. финансовых счетов их резидентов, открытых в офшорных юрисдикциях, а в 2019 - о 84 млн.

По состоянию на октябрь 2021 г. в автоматическом обмене финансовой и налоговой информацией участвуют более 110 юрисдикций [16]. Важно отметить, что участниками автоматического обмена информацией являются не только оншорные юрисдикции, но и офшорные: Бермудские острова, Британские Виргинские острова, Джерси, остров Мэн, Каймановы острова и др. [17]. Участие офшорных юрисдикций в антиофшорной политике является характерной особенностью современности. Содействие этих юрисдикций обусловлено нежеланием лишиться значительных доходов от существующей финансовой деятельности, реализуемой в пределах офшоров, а также социальных и иных выгод.

В результате, признак офшора, заключающийся в предоставлении гарантий конфиденциальности, постепенно теряет свою актуальность. Не исключено, что с течением времени в мире почти не останется юрисдикций, способных обеспечить абсолютную конфиденциальность финансовой информации.

\section{Обеспечение оптимальной правовой сремы $\triangle \wedge$ ве вения бизнеса в офшорных ЮрисАИкШиях}

Об отношении мирового сообщества к предоставлению оптимальной правовой среды для ведения бизнеса в офшорных юрисдикциях можно судить исходя из предпринимаемых антиофшорных мер. Как уже было отмечено ранее, План BEPS направлен на реализацию комплексной налоговой реформы, предусматривающей уравновешивание требований налоговой прозрачности в рамках всех государств. Например, ведение и предоставление налоговой отчетности согласно Плану BEPS осуществляется в рамках унифицированных стандартов.

Условия реализации таких упрощенных условий административного контроля в офшорах, как: упрощенный режим регистрации, отсутствие валютного 
контроля, минимизация числа отчетностей и проверок и др., для компаний-нерезидентов сильно отличаются в зависимости от той или иной офшорной юрисдикции. В рамках каждой из офшорных юрисдикций утверждены индивидуальные правила, порядок и нормы в отношении этих преимуществ. В связи с этим их обобщенный анализ осуществлять некорректно.

Несмотря на то, что для большинства офшорных юрисдикций характерна регистрация компаний-нерезидентов на основании лишь заявления и учредительных документов (или их копий) на английском языке, в ряде офшорных юрисдикций для этого все же требуются дополнительные документы из страны непосредственного ведения бизнеса. Например, минимального пакета документов недостаточно для регистрации компании в офшорных юрисдикциях на территории ЕС. Более того, лишь в немногих офшорных юрисдикциях отсутствуют требования по ведению и предоставлению финансовой отчетности в государственные органы. К таким юрисдикциям относятся Андорра, Коста-Рика, Либерия, Маврикий, Мальдивские острова и др. В большинстве своем, в остальных юрисдикциях компаниям все же необходимо предоставлять отчетности в установленном порядке и с определенной регулярностью $[18$, с. 7].

Практика также показала, что солидные компании сами избегают офшорных юрисдикций, в которых очень высокий уровень конфиденциальности бизнеса, а также отсутствует контроль (в том числе, и валютный) со стороны государственных органов [19, с. 45].

\section{Обшественное неАовольство ук^онением от уп^аты на^огов}

Отличительной чертой борьбы с офшорами стало нарастание общественного недовольства по отношению к уклоняющимся от уплаты налогов физическим и юридическим лицам. Только за последние восемь лет Международным консорциумом журналистов-расследователей (ICIJ) обнародован целый ряд документов, подтверждающих факты причастности к офшорным счетам и использованию офшорных схем многих знаменитых личностей, политиков, спортсменов и компаний. Самыми известными утечками финансовой информации из офшоров являются Offshore Leaks (2013 г.), Panama Papers (2016 г.), Paradise Papers (2017 г.), Pandora Papers (2021 г.). Только над последним расследованием Pandora Papers работу осуществляло более 650 журналистов, которые изучили 11,9 млн. файлов. Фигурантами этого досье стали 30 нынешних и бывших глав государств, а также более 300 чиновников [20].

\section{Выво $\triangle \mathrm{b}$}

Таким образом, антиофшорная политика после мирового экономического кризиса 2008-2009 гг. получила новый виток развития. На международном уровне особенно активно стали разрабатываться и реализовываться меры по деофшоризации мировой экономики. Международными институтами с целью борьбы с основными проблемами в данном направлении, такими как: уклонением от уплаты налогов, конфиденциальностью осуществляемых финансовых операций, сокрытием реальных бенефициаров офшорных компаний и т.д. были инициированы подготовка Плана BEPS, реализация автоматического обмена финансовой и налоговой информацией между государствами.

Многие оншорные государства также стали активными участниками деофшоризации уже не столько на национальном уровне, сколько на мировой арене. Они поддержали вышеупомянутые инициативы ОЭСР и «Большой двадцатки».

В рамках глобальных активных мер по деофшоризации мировой экономики офшорным юрисдикциям ничего не осталось, кроме как смириться с притеснением их деятельности. Понимание тщетности их борьбы за отстаивание своих интересов с остальными заинтересованными сторонами подтолкнуло офшорные юрисдикции идти на компромисс и способствовать реализации глобальной деофшоризации с целью сохранения существующих экономических, социальных и иных выгод.

\section{ЛИТЕРАТУРА}

1. Ярошевич В., Сарган А. Оффшорный сегмент мировой экономики: эволюция и тенденции развития // Банковский вестник. 2013. № 3 (588). с. 33-39. URL: https://www.nbrb.by/bv/articles/9675.pdf (дата обращения: 28.10.2021).

2. Хейфец, Б.А. Офшорные юрисдикции в глобальной и национальной экономике / Хейфец Б.А. — Москва: 3 АО «Издательство «Экономика».— 2008. 335 c. - ISBN978-5-282-02852-2.— - Текст: непосредственный.

3. Tørsløv T., Wier L., Zucman G. The Missing Profits of Nations: 2018 Figures // NBER. — August 2021- Текст: электронный.— URL: https://missingprofits.world (дата обращения: 02.11.2021).

4. Хейфец, Б.А. Деофшоризация российской экономики: возможности и пределы / Б.А. Хейфец — Москва: Институт экономики РАН. - 2013. - 63 c. ISBN978-5-9940-0426-5.— Текст: электронный.—URL: https://inecon.org/docs/Kheifets_2013.pdf (дата обращения: 04.11.2021). 
5. The State of Tax Justice 2020: Tax justice in the time of COVID-19 // Tax Justice Network — November 2020 — URL: https://taxjustice.net (дата 06ращения: 06.11.2021).

6. Шелепов А.В. Проект ВEPS: глобальное сотрудничество в сфере налогообложения // Вестник международных организаций: образование, наука, новая экономика. - Т. 11.— № 4-2016. с. 36-59.— Текст: электронный.— URL: https://cyberleninka.ru (дата обращения: 10.11.2021).

7. Внешнеэкономическая политика России в условиях глобальных рисков / под ред. А.А. Ткаченко. — М.: KУPC, 2018. - 320 c. - ISBN978-5-90706461-4. - Текст: непосредственный.

8. Clausing K., Saez E., Zucman G. Ending Corporate Tax Avoidance and Tax Competition: A Plan to Collect the Tax Deficit of Multinationals // Econometrics Laboratory (University of California, Berkeley).— January 2021-18 p.— Текст: электронный.— URL: https://eml.berkeley.edu (дата 0бращения: 11.11.2021).

9. De Mooij, Ruud, Alexander Klemm, Victoria Perry. Corporate Income Taxes under Pressure: Why Reform Is Needed and How It Could Be Designed // International Monetary Fund. - 2021._ - 376 p. — URL: https://www.elibrary.imf.org (дата обращения: 11.11.2021).

10. Corporate Tax Rates around the World // Tax Foundation. — Текст: электронный.— URL: https://taxfoundation.org (дата обращения: 11.11.2021).

11. OECD Secretary-General Mathias Cormann welcomes outcome of the G20 Leaders Summit // OECD — 31.10.2021 — URL: https://www.oecd.org (дата oбpaщения: 12.11.2021).

12. Mona Barake, Paul-Emmanuel Chouc, Theresa Neef, Gabriel Zucman. Collecting the Tax Deficit of Multinational Companies: Simulations for the European // EU Tax Observatory. — June 2021-57 р.— - Текст: электронный.— URL: https://www.taxobservatory.eu (дата обращения: 12.11.2021).

13. The Era of Bank Secrecy is Over // OECD. — 26 0ctober 2011. — Текст: электронный. — URL: https://www.oecd.org (дата 0бращения: 13.11.2021).

14. Саргсян Л.М. Структура международной системы регулирования офшорных зон: современное состояние и перспективы развития // Вестник Московского университета. Серия 25. Международные отношения и мировая политика. 2016. № 2. c. 31-54.— URL: https://cyberleninka.ru (дата обращения: 13.11.2021).

15. OECD Secretary-General Tax Report to G20 Finance Ministers and Central Bank Governors // OECD — July 2020, 0ECD, Paris. — Текст: электронный. — URL: https://www.oecd.org/ (дата обращения: 13.11.2021).

16. Activated Exchange Relationships for CRS information // OECD — October 2021. — URL: https://www.oecd.org/ (дата обращения: 13.11.2021).

17. CRS by jurisdiction // OECD — URL: https://www.oecd.org (дата обращения: 14.11.2021).

18. Михайлин А.Н., Смирнов Е.Н. Эволюция и современный этап функционирования оффшорных зон в зарубежной и российской практике // Вестник евразийской науки. 2018. № 5. c. 1-15.— URL: https://cyberleninka.ru (дата обращения: 14.11.2021).

19. Ярыгина И.3. Деофшоризация: проблемы и решение // Экономика. Налоги. Право. 2016. № 2. c. 43-50.— URL: http://elib.fa.ru/art2016/bv1974.pdf/ download/bv1974.pdf?lang=en (дата обращения: 14.11.2021).

20. Pandora Papers: утечка офшорных файлов пролила свет на тайное богатство мировых лидеров // BBC — 3 октября 2021.—URL: https://www.bbc.com (дата обращения: 14.11.2021).

( Т Тригуб Екатерина Юрьевна ( ekatrigub@mail.ru).

Журнал «Современная наука: актуальные проблемы теории и практики» 